Gut, 1971, 12, 519-527

\title{
Recurrence of Crohn's disease after primary excisional surgery
}

\author{
F. T. DE DOMBAL, I. BURTON, AND J. C. GOLIGHER
}

From the University Department of Surgery, the General Infirmary, Leeds

SUMMARY The problems associated with recurrent Crohn's disease were examined in a series of 168 patients who had undergone primary resection for this condition at the General Infirmary at Leeds from 1939 to 1968 inclusive.

The overall recurrence rate was $34 \cdot 2 \%$. The risk of recurrence was less in patients with involvement mainly of large bowel rather than small. It was also affected by the age of the patient, being greatest in children or adolescents, less in adults, and least in those over 60 years of age.

Recurrent disease was most commonly found in the small bowel proximal to an anastomosis, and usually manifested itself either in the first year or two after surgery or some five to 15 years later. Patients with 'early' recurrence had a shorter history of symptoms at operation, and a graver outlook than those with 'late' recurrence.

The status of recurrent cases was much better than might have been anticipated in so far as nearly $70 \%$ of them were considered at review to be in very good or good general health. Moreover the risk of further recurrence after a second or third operation was found to be no greater than after a first operation.

The results of radical surgical treatment for ulcerative colitis are unfortunately occasionally marred by the occurrence of quite serious complications and sequelae, which may prove at least temporarily disappointing to surgeon and patient alike. But both can take consolation from the reflection that, after removal of the entire large bowel, there can be no reassertion of the primary disease for which the operation was performed. When we turn to that other major 'inflammatory' process of the intestine with which the surgeon has often to grapple, namely, Crohn's disease, although a similarly complicated convalescence has sometimes to be faced, no such firm assurance can be given. Regrettably Crohn's disease may affect any part of the small or large intestine - and rarely even the duodenum, stomach, oesophagus, pharynx, or indeed tissues entirely outside the alimentary tract. Many reports testify to the great frequency with which, after resection of a lesion from one segment of the intestine, the disease reappears months or years later in another segment. It is certainly no exaggeration to say that the surgery of Crohn's disease has been haunted by the spectre of recurrence. Accordingly, no analysis of the outcome of surgical treatment for Crohn's disease Received for publication 4 May 1971. would be complete without a detailed consideration of the phenomenon of recurrence. As we have recently been examining the collective experience of the Leeds General Infirmary in the surgical management of this disease (de Dombal, Burton, and Goligher, 1971a; Goligher, de Dombal, and Burton, $1971 a$ and b) it seemed appropriate to review our experience of recurrent Crohn's disease at the same time.

\section{Patients and Method of Analysis}

Although 332 patients received treatment for Crohn's disease at the General Infirmary during the 30-year period 1939-68 inclusive, in quite a number of cases the first attendance at the Infirmary was with recurrence following previous surgical treatment elsewhere. For the purposes of the present study it seemed preferable to confine our enquiry to patients who had undergone a primary operation in the Infirmary. There were 244 cases in this category, but in some of them the type of operation performed left diseased bowel in situ, as, for example, when a bypass operation was employed or an abdominal or anal abscess was merely drained. Clearly, from the standpoint of recurrence these latter patients 
introduce semantic difficulties, which we have deemed it wiser to avoid. Accordingly, we have excluded from the analysis the 31 patients treated by bypass operations and another 31 patients who were submitted to miscellaneous irregular operations. Of the 182 remaining patients nine died during the early postoperative period, and another five patients were insufficiently followed up to permit a valid analysis of their individual course and prognosis (Table I). This leaves a total of 168 traced patients, in 79 of whom the disease had been mainly in the small bowel and in 89 mainly in the large bowel, whose subsequent follow up forms the basis of this study of recurrent Crohn's disease.

\section{Definition of Recurrence}

There is clearly a need to define what constitutes recurrence before attempting to analyse this complication. Several authors have essayed such a definition, with somewhat conflicting results. For example, Lennard-Jones and Stalder (1967) have noted that 'recurrence' can be classified in three ways: (1) a relapse in symptoms; (2) as (1), but with radiological and/or surgical evidence of recurrent disease; and (3) further resection for Crohn's disease.

The first definition is open to two major criticisms. First of all it does little to distinguish between persistent diseased tissue left in situ in the bowel at the time of the initial operation, and disease arising de novo in a fresh area of the bowel (Atwell, Duthie, and Goligher, 1965). A more serious objection is that, if the occurrence of symptoms per se is to be accepted as evidence of recurrent disease (without any corroboration by radiological or pathological examination), it may be difficult to distinguish between the effects of recurrent disease and those due to the patient's previous operative treatment. Clearly, if the development of a minor degree of diarrhoea were to be regarded as representing a recurrence (without supporting evidence), most patients after a right hemicolectomy for Crohn's disease would be liable to be classified as suffering from recurrence.

Conversely, the third definition is clearly liable to underestimate the overall recurrence rate since many patients with 'proven' extensive recurrent Crohn's disease may not come to resection.

For the purposes of this enquiry, therefore, we have taken a relapse of symptoms to indicate recurrence only if it was accompanied by firm supporting evidence of further disease from other sources. Since in this series as a whole there was a bias towards surgical treatment, the confirmatory information was usually histopathological. Occasionally, however, we accepted as a recurrence a relapse in symptoms that was accompanied by a definite radiological diagnosis of recurrent disease, based on the criteria outlined elsewhere (de Dombal et al, 1971b).

\section{Findings}

OVERALL RECURRENCE RATES

Of the 168 patients studied, 53 were noted to have developed recurrent Crohn's disease at some stage of their follow up. In 102 patients there was no evidence of recurrence whatsoever either in the review of their case notes or when they presented for formal review in 1968/9, and in the remaining 13 cases there was genuine doubt as to the existence of recurrence at any stage. Usually, in this last group the patient had experienced a transitory return of symptoms, which was unaccompanied by any other evidence of recurrent disease. It is of interest to note that all 13 doubtful cases had either small bowel resection or right hemicolectomy as the primary procedure. If the doubtful cases are included amongst the normal or non-recurrent cases, the incidence of recurrence in the 168 patients is $31.5 \%$; if, on the other hand, the doubtful cases are entirely excluded from the series, the incidence of recurrence becomes $34.2 \%$. It should, however, be noted that 'overall' recurrence figures (though often quoted) are somewhat mis-

\begin{tabular}{|c|c|c|c|c|c|c|c|c|}
\hline Operation & $\begin{array}{l}\text { Times } \\
\text { Performed }\end{array}$ & $\begin{array}{l}\text { Early Post- } \\
\text { operative } \\
\text { Deaths }\end{array}$ & $\begin{array}{l}\text { No. left } \\
\text { Hospital }\end{array}$ & $\begin{array}{l}\text { Lost to } \\
\text { Follow Up }\end{array}$ & $\begin{array}{l}\text { Followed } \\
<6 / 12 y r\end{array}$ & $\begin{array}{l}\text { Total No. } \\
\text { Followed }\end{array}$ & $\begin{array}{l}\text { Late } \\
\text { Deaths }\end{array}$ & $\begin{array}{l}\text { Total No. } \\
\text { Reviewed }\end{array}$ \\
\hline $\begin{array}{l}\text { Small bowel resection (SBR) } \\
\text { SBR + RHC } \\
\text { R hemicolectomy (RHC) } \\
\text { Ileorectal anastomosis } \\
\text { Proctocolectomy } \\
\text { L hemicolectomy } \\
\text { Colectomy }\end{array}$ & $\begin{array}{r}18 \\
69 \\
35 \\
12 \\
39 \\
7 \\
2\end{array}$ & $\begin{array}{l}1 \\
3 \\
2 \\
1 \\
2 \\
-\end{array}$ & $\begin{array}{r}17 \\
66 \\
33 \\
11 \\
37 \\
7 \\
2\end{array}$ & $\begin{array}{l}\overline{3} \\
- \\
- \\
-\end{array}$ & $\begin{array}{l}- \\
1 \\
- \\
-\end{array}$ & $\begin{array}{r}17 \\
62 \\
32 \\
11 \\
37 \\
7 \\
7\end{array}$ & $\begin{array}{l}3 \\
8 \\
2 \\
1 \\
2 \\
1 \\
-\end{array}$ & $\begin{array}{r}14 \\
54 \\
30 \\
10 \\
35 \\
6 \\
2\end{array}$ \\
\hline Total & 182 & 9 & 173 & 3 & 2 & 168 & 13 & 155 \\
\hline
\end{tabular}

Table I Postoperative course of 155 patients after primary surgery for Crohn's disease at the General Infirmary at Leeds 
leading in this context, for reasons which will shortly become apparent.

\section{FACTORS INFLUENCING RECURRENCE}

\section{Age at operation}

Our data confirm the findings of Stahlgren and Ferguson (1961) that there is a clear relationship between the age at operation and the subsequent risk of recurrence (Fig. 1). Recurrence was manifested by 10 or $52.6 \%$ of the 19 patients who came to surgery below the age of 20 years, whilst the frequency of recurrence in the third, fourth, and fifth decades was rather less, and above the age of 50 it dropped sharply, being only $6.7 \%$ amongst the 15 patients aged 60 years or more at the time of the initial surgical treatment. The difference between patients aged 10-49 years and those aged 50 years and over at the time of their primary operation reaches statistical significance at the $1 \%$ level $\left(\chi^{2}=8 \cdot 55, \mathrm{df}=1, \mathrm{P}<0.01\right)$.

\section{Duration of disease at time of operation}

The relationship between the duration of the disease up to the time of the primary operation and the frequency of recurrence is analysed in Table II. It will be seen that the resulting distributional curve is bimodal, the first peak occurring between five and 10 years and the second some six months before surgery. This is best seen on a broken scale, and is of interest in view of similar findings (vide infra) when the timing of postoperative recurrence is considered.

\section{Site of disease}

The widely held clinical impression (Cornes and Stecher, 1961 ; Jones, Lennard-Jones, and LockhartMummery, 1966) that patients with primary large bowel disease show less liability to develop recurrence after surgery than do those in whom disease initially involved the small bowel is confirmed by this study. Of the 30 patients in whom disease was confined to the large bowel at the time of the primary

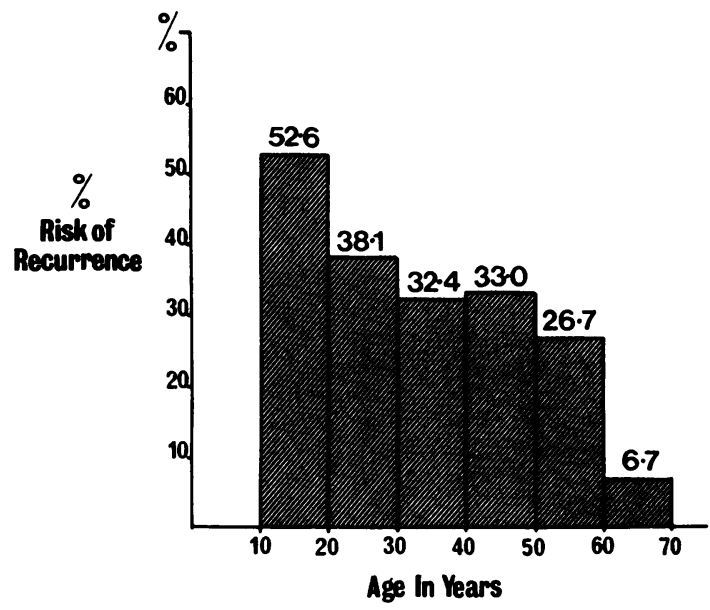

Fig. 1 Relationship between age at time of primary surgery and subsequent risk of recurrence.

operation, only four $(11.8 \%)$ suffered a recurrence during their follow up, whilst 23 of the 60 patients with primary small bowel disease did so $(40.4 \%)$. Perhaps surprisingly, the 64 patients with small and large bowel disease at the time of primary surgery faced much the same risk of recurrence as those with small bowel disease alone $(40.6 \%)$. The difference between patients with lesions completely restricted to the large bowel and the remainder of the series reaches statistical significance $\left(\chi^{2}=6.41\right.$, df $=1$, $P<0.02$ ).

\section{Types of operation employed}

Two aspects of this variable were analysed, namely, the urgency with which surgical intervention was involved, and the specific operative method employed in each instance (Table III). The former consideration seems to have had very little influence on the incidence of recurrent disease. Thus of the 24 patients who underwent urgent or emergency operations, nine or $38 \%$ subsequently developed recurrence,

\begin{tabular}{|c|c|c|c|c|c|}
\hline \multirow[t]{2}{*}{ Duration (yr) } & \multirow[t]{2}{*}{ Patients Followed } & \multicolumn{3}{|c|}{ Recurrence } & \multirow{2}{*}{$\begin{array}{l}\text { Percentage Definite } \\
\text { Recurrence }\end{array}$} \\
\hline & & Yes & No & Doubtful & \\
\hline $\begin{array}{l}<3 / 12 \\
<6 / 12 \\
<1 \\
1-2 \\
2-3 \\
3-5 \\
5-9 \\
10-19 \\
20\end{array}$ & $\begin{array}{r}14 \\
17 \\
26 \\
20 \\
25 \\
27 \\
22 \\
12 \\
5\end{array}$ & $\begin{array}{r}5 \\
7 \\
11 \\
7 \\
3 \\
7 \\
10 \\
2 \\
1\end{array}$ & $\begin{array}{r}6 \\
6 \\
15 \\
11 \\
21 \\
18 \\
11 \\
10 \\
4\end{array}$ & $\begin{array}{l}3 \\
4 \\
2 \\
1 \\
2 \\
1 \\
-\end{array}$ & $\begin{array}{l}45 \cdot 5 \\
53 \cdot 8 \\
42 \cdot 3 \\
38.9 \\
12.5 \\
28.0 \\
47.6 \\
16.7 \\
20.0\end{array}$ \\
\hline Total & 168 & 53 & 102 & 13 & $34 \cdot 2$ \\
\hline
\end{tabular}

Table II Duration of disease at primary operation vs risk of recurrence 
whilst of the 131 cases undergoing elective procedures, 44 or $33.6 \%$ were so complicated.

\begin{tabular}{lcc}
\hline Urgency & No. of Operations & $\begin{array}{l}\text { Patients with Definite } \\
\text { Recurrence }\end{array}$ \\
\hline Urgent/emergency & 24 & $9(38 \cdot 1 \%)$ \\
Elective & 131 & $44(33 \cdot 6 \%)$ \\
Total & 155 & $53(34 \cdot 2 \%)$ \\
\hline
\end{tabular}

Table III Influence of urgency of operation upon incidence of subsequent recurrence ${ }^{1}$

'Excludes 13 patients in whom development of recurrence was doubtful.

Recurrence rates after various specific operative procedures are also shown in Table VI. It is seen that the risk is highest $(60.0 \%)$ after small bowel resection and lowest $(10.8 \%)$ after proctocolectomy. Although the trend will be immediately apparent, it seems not unlikely that this is due to the site of the lesion in the intestinal tract rather than to the particular operative technique employed to deal with it.

\section{Length of diseased segment of intestine}

Previous studies elsewhere (van Patter, Bargen, Dockerty, Feldman, Mayo, and Waugh, 1954; Davis, 1961; Schofield, 1965) and even the Leeds series of cases at an earlier stage (Atwell et al, 1965) have noted an increased risk of recurrence in patients with an extensive area of bowel involved. Unfortunately precise information as to the length of intestine affected was lacking in many of the cases in the present survey, but what data there are indicate rather a trend in the opposite direction. Thus the risk of recurrence was lower after small bowel resection plus right hemicolectomy $(\mathbf{4 0 . 0 \% )}$ than after small bowel resection alone $(60.0 \%)$ and lower after proctocolectomy $(10.8 \%)$ than after any more limited form of colectomy. As an explanation for these differences it could be argued that the more extensive operations left a wider margin of clearance between the lines of resection and the diseased bowel but from our data it is quite clear that this was not generally so. We wonder in retrospect whether part of the previously observed trend (Atwell et al, 1965) might not have arisen from the inclusion in that study of symptomatic recurrences (without objective evidence of recurrence) in the total figures, for it seems plausible to postulate that the more extensive the resection, the more likely it is to be followed by symptoms due to the operation itself.

\section{TIMING OF RECURRENCE}

As shown in Table $V$ most recurrences develop either during the first year or so after surgery, or some five to 15 years later. The curve indicating cumulative recurrence after surgery (Fig. 2) is thus biphasic, and the overall cumulative risk of recurrence predicted by actuarial analysis of our data is $15.5 \%$ after one

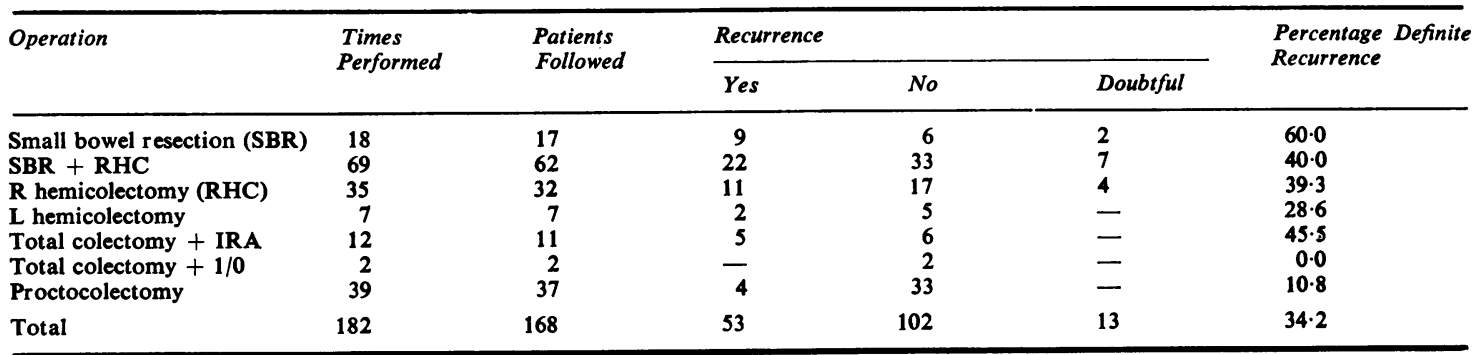

Table IV Incidence of recurrent disease 168 in patients related to type of operation

\begin{tabular}{|c|c|c|c|c|c|c|}
\hline $\begin{array}{l}\text { Period of } \\
\text { Follow Up }(y r)\end{array}$ & $\begin{array}{l}\text { Patients } \\
\text { Followed }\end{array}$ & $\begin{array}{l}\text { Man Years } \\
\text { at Risk }\end{array}$ & $\begin{array}{l}\text { Patients with } \\
\text { Recurrence }\end{array}$ & $\begin{array}{l}\text { No Recurrence } \\
\text { but Not Followed } \\
\text { Further }\end{array}$ & $\begin{array}{l}\text { qx Annual Prob- } \\
\text { ability Recurrence }\end{array}$ & $\begin{array}{l}\text { qx Cumulative } \\
\text { Probability of } \\
\text { Recurrence }\end{array}$ \\
\hline $\begin{array}{l}0-1 \\
1-2 \\
2-3 \\
3-4 \\
4-5 \\
5-9 \\
10-19 \\
20+\end{array}$ & $\begin{array}{r}168 \\
139 \\
108 \\
87 \\
79 \\
69 \\
39 \\
8\end{array}$ & $\begin{array}{r}168 \\
139 \\
108 \\
87 \\
79 \\
257 \\
271 \\
29\end{array}$ & $\begin{array}{r}26 \\
6 \\
3 \\
0 \\
1 \\
9 \\
8 \\
0\end{array}$ & $\begin{array}{r}3 \\
25 \\
18 \\
8 \\
9 \\
21 \\
23 \\
-\end{array}$ & $\begin{array}{l}0.155 \\
0.043 \\
0.028 \\
0.000 \\
0.013 \\
0.035 \\
0.030 \\
-\end{array}$ & $\begin{array}{l}0.155 \\
0.192 \\
0.215 \\
0.215 \\
0.225 \\
0.353 \\
0.523 \\
-\end{array}$ \\
\hline
\end{tabular}

Table V Timing of recurrence after 168 primary resections for Crohn's disease

Difference between yrs 0-2 and 2-5 is significant $\left(x^{2}=18.74, \mathrm{df}=1, \mathrm{P}<0.001\right)$ as is difference between yrs $3-5$ and $5-9(\mathrm{P}$ abs $\approx 0.0089)$ 


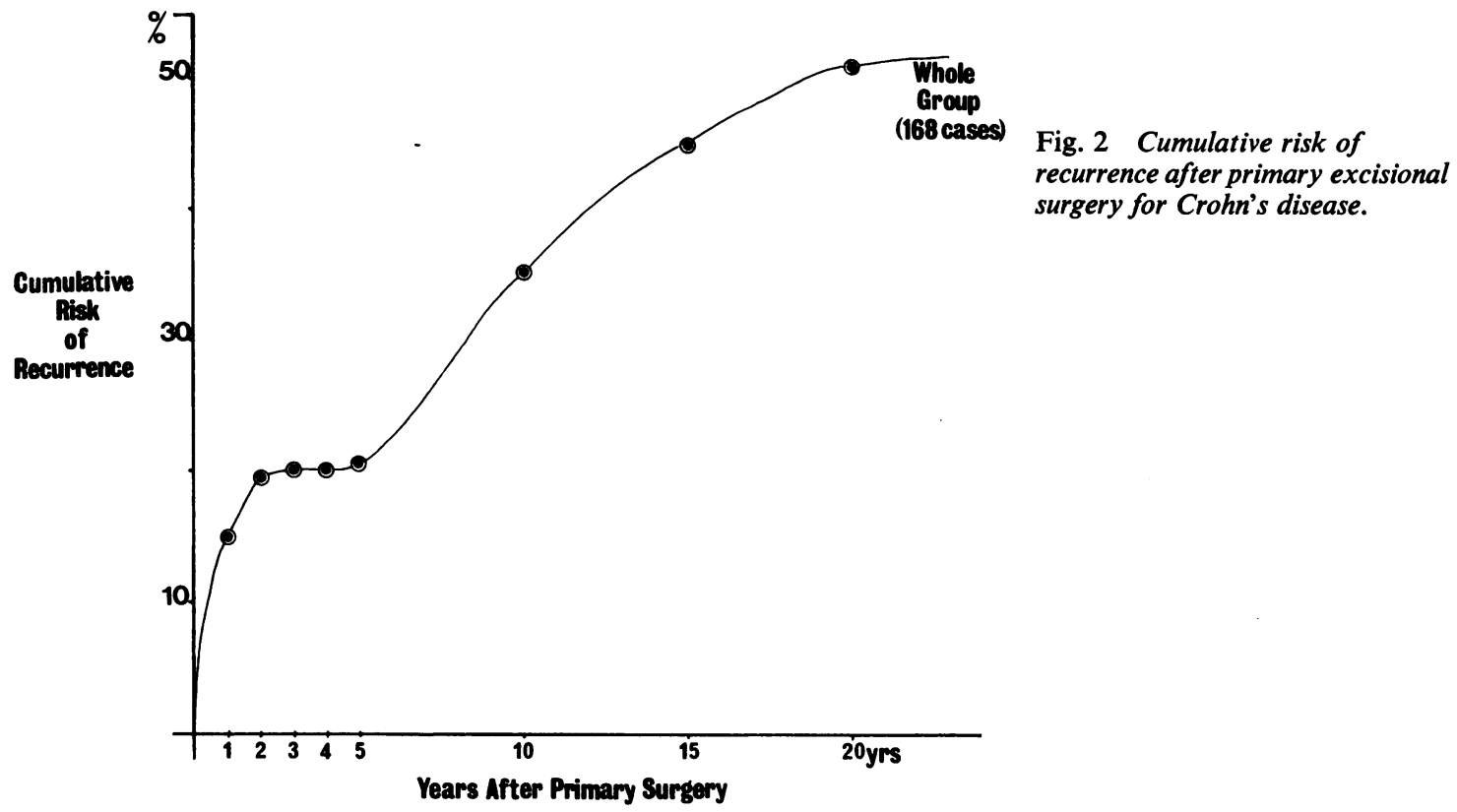

year, $22.5 \%$ after five years, $35.3 \%$ after 10 years, and $52.3 \%$ after 20 years. Figure 3 illustrates cumulative recurrence rates after surgery aimed primarily at the small bowel (79 patients) and large bowel (89 patients). Whilst the incidence of recurrence is throughout lower in patients who had large bowel disease than in those who had had small

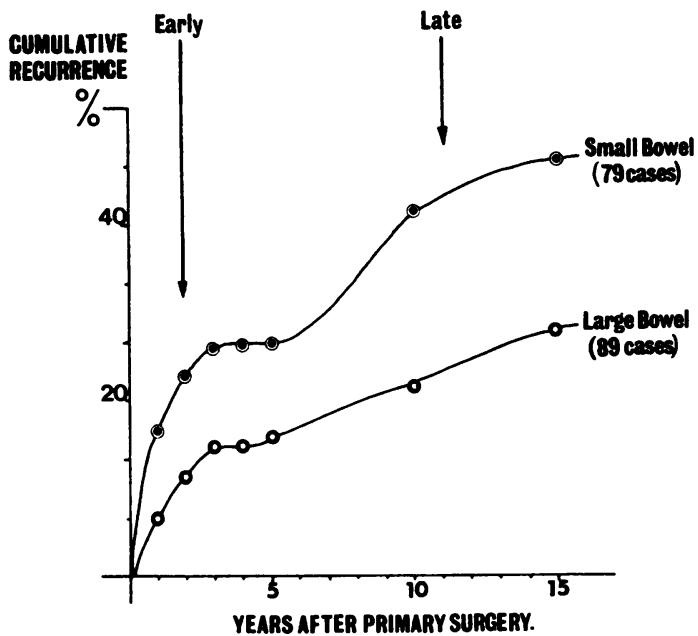

Fig. 3 Cumulative risk of recurrence after surgery for Crohn's disease aimed primarily at small and large bowel lesions. Note two apparent types of recurrence (early and late) and compare with Figures 5, 6, and 7. bowel disease, it is also apparent that both curves are biphasic in nature, though this is seen better in the upper (small bowel) curve.

Effect of different operative procedures on time of development of recurrence

This is analysed in Fig. 4, which illustrates a trend noted earlier, namely, that after extensive resections recurrence of disease tends to be less frequent; it will be noted also that it takes place much later after the initial primary procedure. As emphasized previously, it is not possible with currently available data to determine whether this relationship is due to the type of disease present or to the surgical measures employed to deal with it.

Two further aspects of Fig. 4 are worthy of note. First, the figures for small bowel resection are based upon very small numbers of patients, although it is interesting that nearly half of these patients suffered from recurrence within one year of the primary operation. Secondly, although the results recorded for proctocolectomy patients indicate a favourable prognosis in the medium term, at least three of these patients have suffered from recurrence in the year or so since the survey was closed at the end of 1968 . We have not included these recurrences in our data since they took place after the statistical analysis of our data had been completed, but we have attempted to indicate a possible trend by the dotted line shown in Figure 4. 


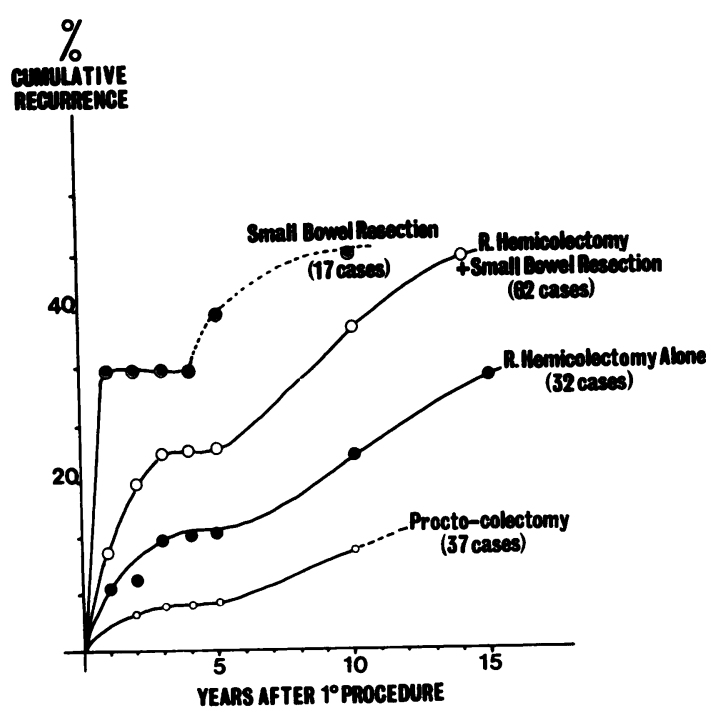

Fig. 4 Cumulative risk of recurrence after specific operative procedures.

\section{SITE OF RECURRENCE}

Table VI shows the site of recurrence in 53 patients, many of whom suffered from recurrence at many separate sites. Table VII which is restricted to patients undergoing resection plus an anastomosis and excludes cases having a resection with a terminal ileostomy or colostomy, indicates whether the recurrent disease was situated proximally or distally to the original diseased and resected bowel. It is seen from these tables that the commonest site of recurrence is in the ileum itself, usually just proximal

\begin{tabular}{lcc}
\hline Site & No. of Recurrences & Percentage of Total \\
\hline Jejunum & 2 & $2 \cdot 8$ \\
Ileum & 44 & 62.0 \\
R colon & 8 & $11 \cdot 3$ \\
Colon & 9 & 12.7 \\
Rectum & 8 & 11.3 \\
Total & 71 & 100.0 \\
\hline
\end{tabular}

Table VI Site of recurrence in 53 patients

\begin{tabular}{llcl}
\hline \multicolumn{4}{l}{ Site of Recurrence } \\
\cline { 2 - 4 } & Proximal & Distal & Both \\
\hline No. of patients & 30 & 7 & 12 \\
Percentage of group & 61.2 & 14.3 & 24.5 \\
\hline
\end{tabular}

Table VII Relationship of recurrence site to original anastomosis in 49 patients $^{1}$

${ }^{1}$ Excludes four patients who suffered recurrence after ileostomy.

to the anastomosis, such a situation being present in approximately two-thirds of the patients who suffered recurrence.

\section{TREATMENT OF RECURRENCE}

Table VIII shows the methods employed in the treatment of recurrent disease in the present series. Of the 53 patients, roughly one-third (17 or $32.1 \%)$ were managed conservatively until the time of their review in 1969. The remaining 36 patients underwent a variety of operative procedures which are listed in Table VIII. It is perhaps surprising to note that bypass was to be employed as the secondary operation after primary resection in seven cases-usually after primary small bowel resection plus right hemicolectomy.

\section{OUTCOME OF RECURRENCE}

The long-term outcome of patients who suffer from recurrent disease was measured in two separate ways in the present survey. First of all, the risk of third and fourth operations was assessed. These are reported elsewhere (de Dombal et al, 1971a), where it is shown that the patient who has undergone a second operation does not face any greater risk of requiring further surgery than does a patient who has undergone only one primary operation.

In addition, we attempted to assess the long-term outlook for patients with recurrence by comparing their outcome at the time of review (Tables IX and $X$ ) with that of the remainder of the patients. As might be expected, patients with recurrence showed themselves in a less favourable light at review than did those without recurrence, whether they were

\begin{tabular}{|c|c|c|c|c|c|}
\hline Primary Operation & Bypass & $\begin{array}{l}\text { Small Bowel } \\
\text { Excision }\end{array}$ & $\begin{array}{l}\text { Large Bowel } \\
\text { Excision }\end{array}$ & Other & None \\
\hline $\begin{array}{l}\text { Proctocolectomy } \\
\text { Ileorectal anastomosis } \\
\text { Small bowel resection (SBR) } \\
\text { L hemicolectomy } \\
\text { R hemicolectomy (RHC) } \\
\text { SBR + RHC }\end{array}$ & $\frac{\bar{z}}{\frac{1}{1}}$ & $\begin{array}{l}2 \\
3 \\
1 \\
1 \\
4 \\
3\end{array}$ & $\begin{array}{l}\frac{7}{3} \\
\frac{3}{2} \\
\frac{7}{2}\end{array}$ & $\begin{array}{l}-1 \\
1 \\
1 \\
6 \\
5\end{array}$ & $\frac{\frac{2}{3}}{11}$ \\
\hline Total & 7 & 14 & 8 & 14 & 17 \\
\hline
\end{tabular}

Table VIII Nature of further operative treatment necessary to deal with recurrence 


\begin{tabular}{|c|c|c|}
\hline \multirow[t]{2}{*}{ Status } & Recurrence & No Recurrence \\
\hline & No. & No. \\
\hline $\begin{array}{l}\text { Very good } \\
\text { Good } \\
\text { Fair }\end{array}$ & $\begin{array}{ll}15 & (32 \cdot 6 \%) \\
17 & (37.0 \%) \\
14 & (30.4 \%)\end{array}$ & $\begin{array}{rr}58 & (54.7 \%) \\
43 & (40.6 \%) \\
5 & (4.7 \%)\end{array}$ \\
\hline Total & $46(100.0 \%)$ & $106(100.0 \%)$ \\
\hline
\end{tabular}

Table IX State of patients' general health at time of review

Recurrence vs No recurrence groups $\left(x^{2}=14 \cdot 19, \mathrm{df}=2, \mathrm{P}<0.0001\right)$ 'This category in Tables IX and $X$ includes 13 patients with 'doubtful' recurrence-in three cases the patients' status could not be adequately assessed on the information available.

\begin{tabular}{|c|c|c|}
\hline & Recurrence & No Recurrence \\
\hline & No. & No. \\
\hline $\begin{array}{l}\text { Satisfied } \\
\text { Satisfied: reservations } \\
\text { ISQ } \\
\text { Worse }\end{array}$ & $\begin{array}{rr}23 & (50.0 \%) \\
11 & (23.9 \%) \\
9 & (19.6 \%) \\
3 & (6.5 \%)\end{array}$ & $\begin{array}{rr}74 & (69.8 \%) \\
28 & (26.4 \%) \\
3 & (2.8 \%) \\
1 & (0.9 \%)\end{array}$ \\
\hline Total & $46(100 \cdot 0 \%)$ & $106(100.0 \%)$ \\
\hline
\end{tabular}

Table X Patients' assessment of outcome of treatment at time of review

Comparing two groups $\left(x^{2}=12.01, \mathrm{df}=2, \mathrm{P}<0.0001\right)$ ('ISQ' \& 'Worse' categories combined)

judged in terms of general health $\left(\chi^{2}=14 \cdot 19\right.$, df $=2, \quad P<0.001)$ or according to their own satisfaction with the operative treatment given $\left(\chi^{2}=12.01, \quad \mathrm{df}=2, \quad \mathrm{P}<0.001\right)$. By contrast, however, there was little difference in the overall death rates for the two groups $(13.2 \%$ for the recurrence patients, $8.7 \%$ for the remainder).

EARLY AND LATE FORMS OF RECURRENCE A most intriguing finding in the present survey has been the biphasic nature of the curves of cumulative recurrence in Figures 2, 3, and 4. Even though the numbers of patients in the various categories are small, this biphasic type of curve seems to be found quite consistently after large or small bowel surgery in general, and also after each individual operative procedure. It thus seems to be a general phenomenon, although there are variations in the individual curves involved. This suggests that there may be two types of recurrence after surgery for Crohn's disease: an 'early' recurrence, in the first two years after operation, and a 'late' recurrence, chiefly some five or 10 years later. In order to test this hypothesis, we carried out a further analysis to determine whether the groups with early and late recurrence differed from each other, either as regards preoperative factors (such as age, duration of disease, and site of involvement), or in terms of their subsequent prognosis.

\section{Composition of groups}

The composition of the two groups of patients is shown in Figures 5 and 6. Patients who suffered an early recurrence were as a group rather younger than their counterparts with late recurrences, and large bowel disease was found exclusively in the former group. Two further features are particularly worthy of note.

First, patients with 'late' recurrence seem a homogeneous group - as measured by such variables as their age at operation and duration of disease. This is not so in the case of the early recurrence group. Thus the curves for the early group in respect of age and duration of disease at operation are bimodal and it may be that there is more than one type of early recurrence involved. It is obviously difficult to be certain in view of the small numbers involved, but it may be that the group of patients with early recurrence contains further small subgroups which our survey has not been able to delineate.

Secondly, and more important, there is an apparent connection between the duration of disease at the time of operation and the timing of subsequent
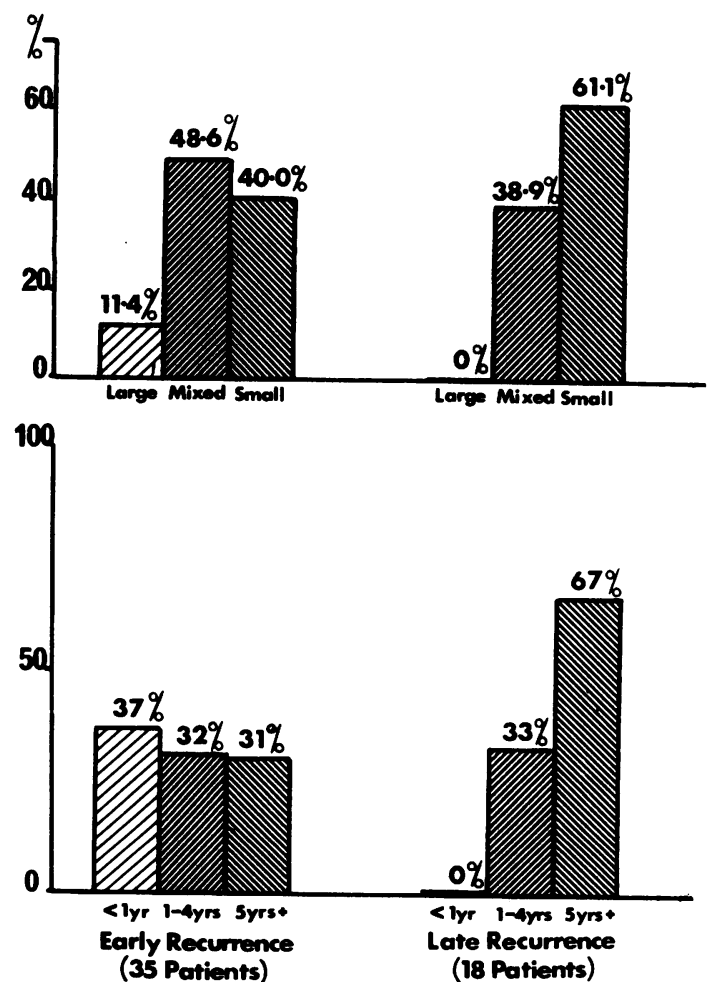

Fig. 5 Comparison of 'early' and 'late' recurrence groups in terms of extent of disease $(\mathrm{P}>0.1)$ and duration of disease at primary operation $(\mathrm{P}<0.01)$. 


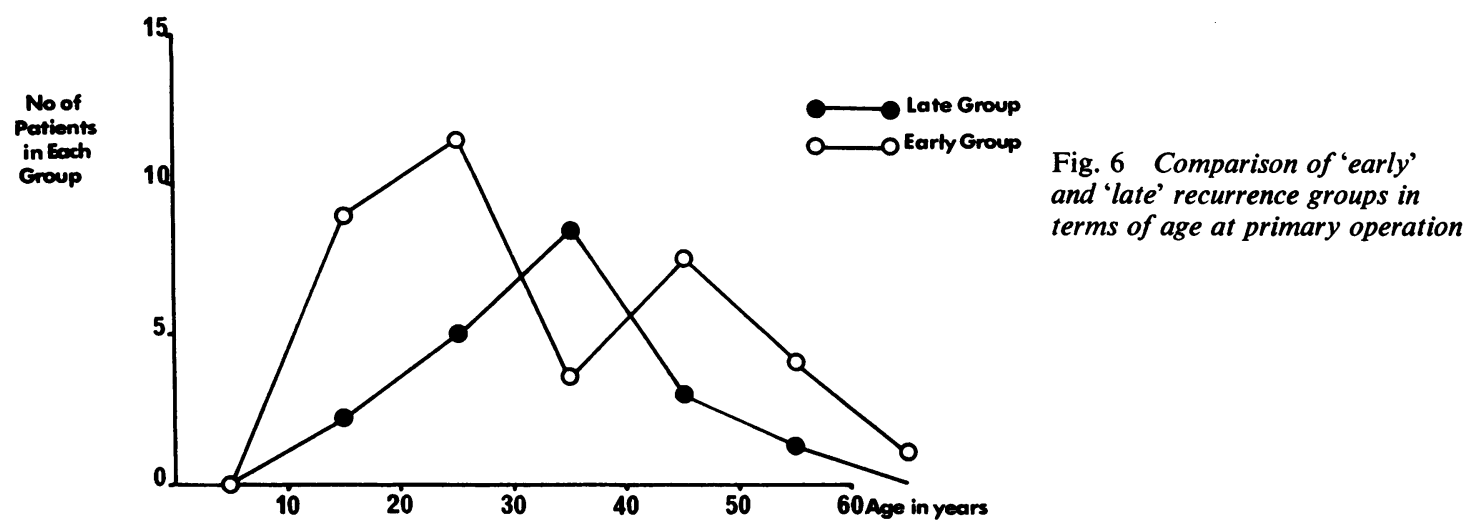

recurrence. Thirteen of the 35 early recurrence patients had a history of less than one year at operation, whilst none of the 18 patients with late recurrence had a history of less than 14 months. Even with the small groups involved, this difference is statistically significant at the $1 \%$ level.

\section{Subsequent prognosis}

Our analysis (Fig. 7) shows that there is a marked difference between the groups with early and late recurrence respectively in respect of mortality rate
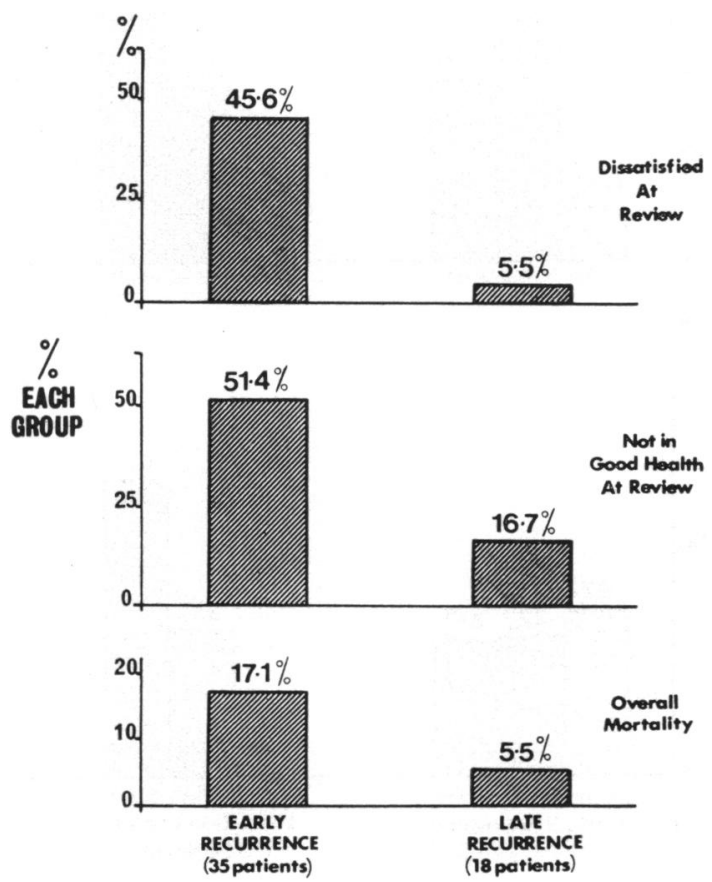

Fig. 7 Comparison of outcome of treatment in 'early' and 'late' recurrence groups. and status at review. Six of the 'early' patients died $(17 \cdot 1 \%)$, as compared with only one of the 'late' group $(5.5 \%)$, a difference, however, that is not statistically significant. Neither, indeed, are the findings at review, although on the face of it these seem quite striking. Thus, only half of the group of patients with early recurrence were in good or very good general health (17 or $48.6 \%$ out of 35 ), as contrasted with all but three of those with late recurrence $(83.3 \%)$. Moreover, only 19 or $54.3 \%$ of the patients with early recurrence were satisfied with the results of their treatment, compared with all but one of the late group $(94.5 \%)$. These differences just fail to reach statistical significance $\left(\chi^{2}\right.$ for the two analyses being 2.79 and 3.68 respectively).

\section{Discussion}

Previous studies of recurrent Crohn's disease (van Patter et al, 1954; Crohn and Yarnis, 1958; Pollock, 1958; Colcock and Vansant, 1960; Gump and Lepore, 1960; Stahlgren and Ferguson. 1961; Barber, Waugh, Beahrs, and Sauer, 1962; Edwards, 1964; Atwell et al, 1965; Schofield, 1965; Lennard-Jones and Stalder, 1967) seem to have assumed that recurrence is a homogeneous phenomenon. Our data, despite the problems inherent in a retrospective survey going back over $\mathbf{3 0}$ years, throw considerable doubt on this assumption for they suggest that at least two types of recurrence (early and late) can be identified according to the length of time that has elapsed between operation and the development of recurrent disease. The groups of patients with early and late recurrences are shown to have different age distributions, different lengths of history at the time of primary operation, and markedly differing prognoses, as measured by the overall mortality rates and the status of the patients at the time of their review in 1968. 
Of particular interest is the finding that all of the patients with a history of less than one year's symptoms at the time of primary surgery who suffered a recurrence of disease did so within two years of their initial operation. This link between the preoperative course of the disease and the patient's postoperative course raises a number of interesting queries. For example, it would be possible to speculate that there are (at least) two types of Crohn's disease rather than two types of recurrence, each with a different prognosis. Type $\mathbf{A}$ has a rapid course, leading to early surgery and a high risk of early recurrence-with a poor subsequent prognosis. Type B develops more slowly, leads to later surgery, and a lower risk of (late) recurrence with (usually) a good prognosis. But such questions cannot be answered on the basis of the data presented in this report.

\section{PROGNOSIS AFTER RECURRENCE}

Many of the previous reports concerning the outcome of surgical treatment for Crohn's disease have painted an extremely sombre picture on account of the high recurrence rate. Whilst unquestionably recurrence is common, and this is confirmed by our enquiry, it seems to us that the situation is not one of entirely unrelieved gloom. For one thing, contrary to what might have been expected and has been reported by Lennard-Jones and Stalder (1967), the risk of recurrence after reoperations is not progressively greater than following an initial operation. If anything the chances of recurrent disease arising after third and fourth operations are diminished. Secondly, so far as their status at review is concerned, even though patients with recurrence fared worse than those without recurrence (see Tables IX and X), some $70 \%$ of the recurrent cases were in good or very good health, and roughly three-quarters were satisfied with the outcome of the treatment. This is by no means an entirely depressing situation.

Another important point to be taken into account when considering recurrence as a prognostic factor is our delineation of two or more types of recurrence, each apparently with its own individual prognosis. It would seem to us to be misleading to base a prognosis merely on the fact that recurrence has taken place, without specifying the length of time between primary operation and the development of recurrent disease. For example, less than half of the patients in our early recurrence group were in good or very good general health at review, and only $54 \%$ were satisfied with the results of their treatment, the corresponding figures for the late recurrence group were $83 \%$ and $94.5 \%$ respectively.

We feel, therefore, that the development of recurrence as such is not an ideal criterion upon which to base a judgment of the results of surgery for Crohn's disease. As outlined elsewhere (de Dombal et al, 1971a) we believe that surgery should be undertaken in this condition largely for the relief of symptoms, and it is mainly on its efficacy in so doing that it should be assessed.

One of us (I.B.) was helped by a grant from the Board of Governors of the Leeds General Infirmary, assistance which we acknowledge with gratitude. We also thank the surgeons and physicians of the General Infirmary for permission to study patients under their care.

\section{References}

Atwell, J. D., Duthie, H. L., and Goligher, J. C. (1965). The outcome of Crohn's disease. Brit. J. Surg., 52, 966-972.

Barber, K. W., Jr., Waugh, J. M., Beahrs, O. H., and Sauer, W. G. (1962). Indications for and the results of the surgical treatment of regional enteritis, Ann. Surg., 156, 472-482.

Colcock, B.P., and Vansant, J. H. (1960). Surgical treatment of regional enteritis. New Engl. J. Med., 262, 435-439.

Cornes, J. S., and Stecher, M. (1961). Primary Crohn's disease of the colon and rectum. Gut, 2, 189-201.

Crohn, B. B., and Yarnis, H. (1958). Regional Enteritis, 2nd ed. Grune and Stratton, New York.

Davis, J. M. (1961). The prognosis of Crohn's disease of the small intestine. Postgrad. med. J., 37, 783-791.

De Dombal, F. T., Burton, I., and Goligher, J. C. (1971a). The early and late results of surgical treatment for Crohn's disease. Brit. J. Surg. In press.

De Dombal, F. T., Burton, I., and Goligher, J C. (1971b). The natural history of Crohn's disease. In preparation.

Edwards, H. (1964). Crohn's disease. J. roy. Coll. Surg., Edin., 9, 115-127.

Goligher, J. C., de Dombal, F. T., and Burton, I. (1971a). The surgical treatment of Crohn's disease, and its results. In Skandia International Symposium on Regional Enteritis, Crohn's disease, Stockholm. In press.

Goligher, J. C., de Dombal, F. T., and Burton, I. (1971b). On Crohn's disease: with special reference to surgical management. In Progress in Surgery, Karger, Basle. In press.

Gump, F. and Lepore, M. J. (1960). Prognosis in acute and chronic regional enteritis. Gastroenterology, 39, 694-701.

Jones, J. H., Lennard-Jones, J. E., and Lockhart-Mummery, H. E. (1966). Experience in the treatment of Crohn's disease of the large intestine. Gut, 7, 448-452.

Lennard-Jones, J. E., and Stalder, G. A. (1967). Prognosis after resection of chronic regional ileitis, Gut, 8, 332-336.

Pollock, A. V. (1958). Crohn's disease. Brit. J. Surg., 46, 193-206.

Schofield, P. F. (1965). The natural history and treatment of Crohn's disease. Ann. roy. Coll. Surg., 36, 258-279.

Stahlgren, L. H., and Ferguson, L. K. (1961). The results of surgical treatment of chronic regional enteritis. J. Amer. med. Ass., 175, 986-989.

Van Patter, W. N., Bargen, J. A., Dockerty, M. B., Feldman, W. H., Mayo, C. W., and Waugh, J. M. (1954) Regional enteritis. Gastroenterology, 26, 347-450. 